\title{
ANALISA PENGETAHUAN IBU NIFAS TERHADAP TANDA BAHAYA BAYI BARU LAHIR
}

\section{THE ANALYSIS OF OF POSTPARTUM MOTHER TO KNOWLEDGE THE DANGER SIGNS OF NEW BORN}

\author{
Nur Hidayah ${ }^{1}$, Fitri Wulandari ${ }^{2}$ \\ Prodi DIII Kebidanan STIKES PKU Muhammadiyah Surakarta \\ hidayahnurhidayah19@yahoo.com
}

\begin{abstract}
Abstrak
Angka Kematian Anak tetap menjadi masalah serius di Indonesia. Dari data survei demografi angka kematian balita sebesar 44 per 1000 kelahiran hidup. Angka kematian bayi 34 per 1000 kelahiran hidup dan angka kematian neonatal 19 per 1000 kelahiran hidup. Angka kematian bayi di Kabupaten Karanganyar 116,34 per 100.000 kelahiran hidup. Kematian bayi baru lahir (87\%) dapat dicegah apabila dideteksi dini bayi resiko cepat diketahui.Tujuan penelitian ini untuk mengetahui karakteristik responden berdasarkan umur, pendidikan, pekerjaan dan gambaran tingkat pengetahuan ibu nifas tentang tanda bahaya bayi baru lahir di RSUD Karanganyar Tahun 2013. Penelitian menggunakan metode deskriptif kuantitatif. Penelitian ini dilaksanakan di RSUD Karanganyar. Populasi penelitian adalah seluruh ibu nifas yang dirawat di Bangsal Kenanga RSUD Karanganyar bulan Mei 2013. Jumlah sampel sebanyak 58 responden. Teknik pengambilan sampel adalah teknik accidental sampling. Instrumen penelitian menggunakan kuesioner. Analisa data dengan analisa univariat. Hasil penelitian menunjukkan bahwa pengetahuan ibu nifas tentang tanda bahaya bayi baru lahir responden dengan tingkat pengetahuan baik, yaitu sebanyak 14 responden (24,1\%), responden dengan pengetahuan cukup sebanyak 34 responden (58,6\%),), dan sebagian besar dengan tingkat pengetahuan kurang, yaitu sebanyak 10 responden (17,2\%). Tingkat pengetahuan ibu nifas tentang tanda bahaya bayi baru lahir, sebagian besar dengan tingkat pengetahuannya cukup.
\end{abstract}

Kata kunci: Pengetahuan, ibu nifas, bayi baru lahir, tanda bahaya

\begin{abstract}
Child Mortality remains a serious problem in Indonesia. From the survey data demographic child mortality at 44 per 1,000 live births. The infant mortality rate 34 per 1,000 live births and the neonatal death rate was 19 per 1,000 live births. The infant mortality rate in Karanganyar 116.34 per 100,000 live births. Newborn deaths (87\%) can be prevented if detected early risk infants quickly. The aim of this research is to know the characteristics of respondents by age, education, job and a description of the level of knowledge about the danger signs of postpartum mothers of newborns in hospitals Karanganyar 2013. Research using quantitative descriptive method. This research was conducted in hospitals Karanganyar. The population was all postpartum mothers who were treated in Ward Kenanga Karanganyar District Hospital in May 2013. The samples were 58 respondents. The sampling technique was accidental sampling technique. The research instrument used was questionnaire. Analysis of the data by univariate analysis. Result shows that knowledge postpartum mothers on newborn danger signs respondents with good knowledge level, was 14 respondents $(24.1 \%)$, respondents with sufficient knowledge was 34 respondents (58.6\%)), and most with level lack of knowledge, was 10 respondents (17.2\%). The level of knowledge about the danger signs of postpartum mothers newborns, most with enough knowledge level.
\end{abstract}

Keywords: Knowledge, puerperal women, newborns, danger sign 


\section{PENDAHULUAN}

Angka kematian anak tetap menjadi masalah serius di Indonesia Beberapa penyebab kematian bayi baru lahir (neonates) yang terbanyak disebabkan oleh kegawat daruratan dan penyulit pada masa neonates seperti berat bayi lahir rendah, asfiksia neonatorum, syndrome gawat nafas, hiperbilirubenemia, sepsis neonatorum, trauma lahir dan kelainan congenital. World Health Organization (WHO) menyatakan penyebab langsung kematian neonatus adalah infeksi (32\%), asfiksia (29\%), komplikasi prematuritas (24\%), kelainan bawaan (10\%), dan lain-lain (5\%) (Depkes RI, 2012).

Kematian bayi baru lahir (87\%) dapat dicegah apabila deteksi dini bayi resiko cepat diketahui, dan dapat segera dirujuk agar mendapat pertolongan yang akurat, dan cepat. Diperkirakan tiap jam terdapat 12 neonatus meninggal. Dari sumber SKRT 2001, ternyata dari bayi yang mendapat masalah, yang mencari pertolongan pada tenaga kesehatan hanyalah $36 \%$. Oleh karena itu, tenaga kesehatan di lini terdepan baik di pelayanan perifer ataupun di pusat, sangat diharapkan mempunyai keterampilan baik deteksi dini bayi resiko ataupun penanganan kegawatan, dan menentukan waktu yang tepat kapan bayi akan dirujuk, dan persiapan apa yang harus dilakukan. Bayi yang berumur kurang dari tujuh hari, kelainan yang diderita lebih banyak terkait dengan kehamilan dan persalinan, sedangkan bayi berumur lebih dari tujuh hari sampai dua bulan banyak terkait dengan pola penyakit anak. Karena kebanyakan bayi baru lahir yang sakit jarang di bahwa oleh orang tua ke pusat pelayanan karena kultur masyarakat, maka kunjungan rumah bagi tenaga kesehatan sangat diperlukan, dengan ASUH yaitu awal sehat untuk hidup sehat (Indarso, 2012).

Kematian bayi adalah kematian yang terjadi antara saat bayi lahir sampai bayi belum berusia tepat satu tahun. Banyak factor yang dikaitkan dengan kematian bayi. Secara garis besar, dari sisi penyebabnya, kematian bayi ada dua macam yaitu endogen dan eksogen. Kematian bayi endogen atau yang umum disebut dengan kematian neonatal adalah kematian bayi yang terjadi pada bulan pertama setelah dilahirkan, dan umumnya disebabkan oleh factor-faktor yang dibawa anak sejak lahir, yang diperoleh dari orang tuanya pada saat konsepsi atau didapat selama kehamilan. Kematian bayi eksogen atau kematian post neonatal, adalah kematian bayi yang terjadi setelah usia satu bulan sampai menjelang usia satu tahun yang disebabkan faktor-faktor yang bekaitan dengan pengaruh lingkungan luar (BPS, 2012).

Bayi baru lahir biasanya mudah sakit. Gejala sakit pada bayi baru lahir memang sulit untuk dikenali, untuk itu sudah seharusnya orang tua dapat mengenali tanda-tanda bahaya secara dini pada bayi mereka sebelum keadaan bayi mereka semakin serius karena terlambat membawa ke tempat pelayanan kesehatan dapat berujung kematian. Seorang bayi dengan tanda bahaya merupakan masalah yang serius, bayi dapat meninggal bila tidak ditangani segera (Kosim, 2005; h.1).

Tanda-tanda bahaya bayi baru lahir merupakan suatu gejala yang dapat mengancam kesehatan bayi baru lahir, bahkan dapat menyebabkan kematian. Maka dari itu sudah seharusnya orang tua mengetahui tanda-tanda bahaya terhadap bayi baru lahir yaitu: bayi tidak mau menyusu atau muntah, kejang, lemah, sesak nafas, rewel, pusar kemerahan, demam, suhu tubuh dingin, mata bernanah, diare, bayi kuning (Muslihatun, 2010; h. 46).

Pengetahuan tentang tanda bahaya baru lahir sangatlah penting. Dengan mengetahui tanda bahaya, bayi akan lebih cepat mendapat pertolongan sehingga dapat mencegahnya dari kematian. Namun apabila terlambat dalam pengenalan dari tanda bahaya tersebut, bayi bisa meninggal. Bayi baru lahir mempunyai masalah berat yang dapat mengancam kehidupannya dan memerlukan diagnose dan pengelolaan segera, terlambat dalam pengenalan masalah dan manajemen yang tepat dapat mengakibatkan kematian (Kosim, 2005; h.1).

\section{METODE PENELITIAN}

Penelitian ini menggunakan metode deskriptif kuantitatif. Lokasi penelitian dilaksanakan di RSUD Karanganyar, dengan waktu penelitian pada bulan Mei 2013. Populasi dalam penelitian ini adalah seluruh ibu nifas yang dirawat di Bangsal Kenanga RSUD Karanganyar bulan Mei 2013 dengan jumlah 135 orang, besarnya sampel dalam penelitian sebanyak 58 orang. Teknik pengambilan sampel dalam penelitian ini menggunakan teknik total sampling.

Variabel dalam penelitian ini adalah variabel tunggal, yaitu analisa gambaran pengetahuan ibu nifas tentang tanda bahaya bayi baru lahir. 
Instrumen penelitian menggunakan kuesioner untuk memperoleh data tingkat pengetahuan ibu nifas tentang tanda bahaya bayi baru lahir, dengan jumlah item kuesioner sebanyak 33 pertanyaan. Teknik analisa data yang digunakan dalam penelitian ini adalah dengan menggunakan analisa univariat yaitu menganalisa terhadap tiap variabel dari hasil tiap penelitian untuk menghasilkan distribusi frekuensi dan prosentase dari tiap variabel

\section{HASIL DAN PEMBAHASAN}

\section{Hasil Penelitian}

1. Distribusi Karakteristik Responden Berdasarkan Umur

Berdasarkan hasil penelitian menunjukkan responden dengan umur 21-25 tahun sebanyak 11 responden (19\%), responden dengan umur 26-30 tahun, yaitu sebanyak 28 responden $(48,3 \%)$, responden dengan umur 31-35 tahun yaitu sebanyak 13 responden $(22,4 \%)$, dan responden dengan umur $36-40$ tahun yaitu sebanyak 6 responden $(10,3 \%)$.

2. Karakteristik Responden Berdasarkan pendidikan

Berdasarkan hasil penelitian dapat diketahui responden dengan pendidikan SD sebanyak 3 responden $(5,2 \%)$, responden dengan pendidikan SMP sebanyak 24 responden $(41,4 \%)$, dan responden dengan pendidikan SMA sebanyak 31 responden $(53,4 \%)$.

3. Distribusi Responden Berdasarkan Pekerjaan

Berdasarkan hasil penelitian dapat diketahui responden yang bekerja sebagai wiraswasta atau pedagang sebanyak 12 responden $(20,7 \%)$, responden yang bekerja sebagai swasta sebanyak sebanyak 17 responden $(29,3 \%)$, responden yang tidak bekerja atau ibu rumah tangga (IRT) sebanyak 18 responden $(31 \%)$, responden dengan pekerjaan sebagai buruh sebanyak 9 responden $(15,5 \%)$, dan responden bekerja sebagai PNS, yaitu sebanyak 2 responden $(3,4 \%)$.

4. Tingkat Pengetahuan Ibu Nifas Tentang Tanda Bahaya Bayi Baru Lahir di RSUD Karanganyar Tahun 2013

Berdasarkan hasil penelitian tersebut dapat diketahui pengetahuan ibu nifas tentang tanda bahaya bayi baru lahir responden dengan tingkat pengetahuan baik, yaitu sebanyak 14 responden $(24,1 \%)$, responden dengan pengetahuan cukup sebanyak 34 responden $(58,6 \%)$, dan sebagian responden dengan tingkat pengetahuan kurang, yaitu sebanyak 10 responden $(17,2 \%)$.

\section{Pembahasan}

1. Karakteristik Responden

a. Umur

Hasil penelitian pada Gambar 1 menunjukkan umur ibu nifas sebagian besar dengan umur 26-30 tahun sebanyak 28 responden $(48,3 \%)$. Umur dapat mempengaruhi tingkat pengetahuan seseorang. Menurut Mubarak (2011) dengan bertambahnya umur seseorang akan terjadi perubahan pada aspek fisik dan psikologis (mental), sehingga akan mempengaruhi pengetahuan responden tentang tanda bahaya bayi baru lahir.

b. Pendidikan

Hasil penelitian Pada Gambar 2 menunjukkan sebagian besar responden dengan tingkat pendidikan SMA sebanyak 31 responden $(53,4 \%)$, hal ini menunjukkan responden dengan pendidikan yang baik sehingga akan mempengaruhi baiknya tingkat pengetahuan. Menurut Notoatmodjo (2010), pendidikan dapat mempengaruhi seseorang termasuk juga perilaku seseorang akan pola hidup terutama dalam memotivasi untuk sikap berperan serta dalam pembangunan, pada umumnya makin tinggi pendidikan seseorang makin mudah menerima informasi. Tingkat pendididikan seseorang sangat mempengaruhi pengetahuannnya. Hal ini disebabkan semakin baik pendidikan yang diperoleh, maka semakin mudah dalam menyerap informasi yang diterima. Menurut Mubarak (2011) makin tinggi pendidikan seseorang semakin mudah pula mereka menerima informasi, dan pada akhirnya makin banyak pula penge-tahuan yang dimiliki semakin tinggi tingkat pengetahuannya, dari hasil penelitian dikemukakan tingkat pendi-dikan paling tinggi adalah SMA maka dari itu semakin mudah dalam mendapatkan ingformasi tentang tanda bahaya bayi baru lahir sehingga pengetahuan tentang tanda bahaya bayi baru lahir semakin tinggi. 
c. Pekerjaan

Berdasarkan hasil penelitian menunjukkan jenis pekerjaan ibu nifas sebagian besar ibu nifas dengan tidak bekerja atau ibu rumah tangga (IRT) sebanyak 17 responden (29,3\%). Pekerjaan dapat mempengaruhi pengetahuan. Menurut Mubarak (2011) lingkungan pekerjaan dapat menjadikan seseorang memperoleh pengalaman dan pengetahuan baik secara langsung maupun secara tidak langsung. Dari hasil penelitian dikemukakan tingkat pekerjaan paling tinggi adalah Ibu Rumah Tangga (IRT), karena pekerjaan dan lingkungan dapat menjadikan seseorang memperoleh pengalaman, dan pengetahuan tentang tanda bahaya bayi baru lahir.

\section{Pengetahuan Ibu Nifas Tentang Tanda Bahaya} Bayi Baru Lahir

Pengetahuan ibu nifas tentang tanda bahaya bayi baru lahir responden dengan tingkat pengetahuan baik, yaitu sebanyak 14 responden $(24,1 \%)$, responden dengan pengetahuan cukup sebanyak 34 responden $(58,6 \%)$, dan sebagian besar dengan tingkat pengetahuan kurang, yaitu sebanyak 10 responden $(17,2 \%)$. Tingkat pengetahuan ibu nifas tentang tanda bahaya bayi baru lahir, sebagian besar dengan tingkat pengetahuannya cukup.

Pengetahuan ibu nifas tentang tanda bahaya bayi baru lahir yang dikaji dalam penelitian ini berdasarkan indikator pengertian tanda bahaya baru lahir, tanda-tanda bahaya baru lahir dan penanganan tanda bahaya bayi baru lahir.

Menurut Notoatmodjo (2007) pada dasarnya pengetahuan merupakan hasil dari tahu dan terjadi setelah orang melakukan penginderaan terhadap suatu obyek tertentu. Penginderaan terjadi melalui panca indra manusia yakni indra penglihatan, pendengaran, penciuman, rasa dan raba. Sebagian besar pengetahuan manusia diperoleh melalui mata dan telinga.

Pendidikan dapat mempengaruhi seseorang termasuk juga perilaku seseorang akan pola hidup terutama memotivasi dalam pembangunan pada umumnya semakin tinggi pendidikan seseorang semakin mudah dalam menerima informasi. Pekerjaan pada umumnya kegiatan yang menyita waktu namun dengan bekerja ibu dapat mempengaruhi terhadap kehidupan keluarganya. Umur semakin cukup umur, tingkat kematangan dan kekuatan seseorang akan lebih matang dalam berfikir dan bekerja.

Pengetahuan responden tentang tanda bahaya bayi baru lahir diperoleh melalui pendidikan, pekerjaan dan umur. Pendidikan mempengaruhi responden yang sebagian besar SMA dalam memperoleh pengetahuan tentang tanda bahaya bayi baru lahir, dan sebagian besar dengan umur 26-30 tahun termasuk umur yang matang sehingga lebih matang juga dalam berfikir setelah mendapatkan informasi tentang tanda bahaya bayi baru lahir.

Berdasarkan hasil penelitian dapat diketahui pengetahuan ibu nifas tentang tanda bahaya bayi baru lahir kebanyakan responden mengetahui tentang tanda bahaya bayi baru lahir adalah tanda-tanda bahaya pada bayi baru lahir harus dideteksi lebih dini untuk segera dilakukan penanganan agar tidak mengancam nyawa bayi. Sedangkan menurut teori yang dikemukakan (Muslihatun, 2008; 46) tanda bahaya bayi baru lahir harus di waspadai, dideteksi lebih dini untuk segera dilakukan penanganan agar tidak mengancam nyawa bayi, dalam hal ini tidak ada kesenjangan antara teori dan hasil penelitian. Hal ini menunjukkan responden sudah cukup memahami dengan baik mengenai tanda bahaya bayi baru lahir.

Hasil penelitian pada indikator penanganan tanda bahaya bayi baru lahir responden mengetahui tentang penanganan pada bayi yang sulit bernafas yaitu dengan membersihkan rongga hidung dan mulut. Sedangkan menurut teori yang dikemukakan oleh Mochtar (2008: h. 427) dengan meletakkan bayi dengan posisi terlentang di tempat keras dan hangat kemudian membersihkan hidung, rongga mulut dan tenggorokan bayi dengan jari tangan yang dibungkus kassa steril. Berdasarkan hasil penelitian dan hasil teori yang ada tidak ada kesenjangan yaitu, responden mengetahui tentang penanganan pada bayi yang sulit bernafas yaitu dengan membersihkan rongga hidung dan mulut. 


\section{KESIMPULAN}

Berdasarkan hasil penelitian yang telah dilakukan tentang tingkat pengetahuan ibu nifas tentang tanda bahaya bayi baru lahir dapat disimpulkan:

1. Karakteristik responden tentang tanda bahaya bayi baru lahir berdasarkan umur, sebagian besar dengan umur 26-30 tahun sebanyak 28 responden $(48,3 \%)$.

2. Karakteristik responden tentang tanda bahaya bayi baru lahir berdasarkan umur, sebagian besar responden dengan tingkat pendidikan SMA sebanyak 31 responden $(53,4 \%)$.

3. Karakteristik responden tentang tanda bahaya bayi baru lahir berdasarkan umur, sebagian besar ibu nifas dengan tidak bekerja atau ibu rumah tangga (IRT) sebanyak 17 responden $(29,3 \%)$.

4. Pengetahuan responden tentang tanda bahaya bayi baru lahir dalam kategori cukup sebanyak 34 responden $(58,6 \%)$.

\section{REFERENSI}

BPS, 2012. Angka Kematian Bayi. Tersedia di http://www.datastatistikindonesia.com/portal diunduh tanggal 25 Februari 2013

Depkes RI, 2012. Materi Advokasi Bari Baru Lahir. Tersedia di www.depkes.go.id diunduh tanggal 12 Februari 2013.
2012. Perawatan Bayi Baru Lahir. Jakarta: Direktorat Bina Kesehatan Anak.

Indarso, 2012. Penatalaksanaan Bayi Baru Lahir Dari Ibu Yang Bermasalah. Jurnal Kesehatan. Bag./SMF Ilmu Kesehatan Anak FK Unair/RSU Dr. Soetomo Surabaya.

Kosim, S.M. 2005. Buku Panduan Manajemen Masalah Bayi Baru Lahir untuk Dokter, Perawat, Bidan di Rumah Sakit Rujukan Dasar. Jakarta: JNPK.

Mochtar, Rustam. 2008.Sinopsis obstetri: obstetri operatif, obstetri social. Jilid 2. Jakarta: EGC.

Mubarak, W. I. 2011. Promosi Kesehatan untuk Kebidanan. Jakarta: Salemba medika.

Muslihatun, 2008. Asuhan Neonatus dan Balita. Yogyakarta: Fitramaya.

Notoatmodjo, S. 2007. Promosi Kesehatan Teori dan Aplikasi.Jakarta: Rineka Cipta.

.2010. Metodologi Penelitian Kesehatan.Jakarta: Rineka Cipta 